\title{
The formation of nanostructured surfaces by electrochemical techniques: a range of emerging surface finishes. Part 2: examples of nanostructured surfaces by plating and anodising with their applications
}

\author{
F. C. Walsh*1,2 C. Ponce de León ${ }^{1}$, D. V. Bavykin ${ }^{1,2}$, C. T. J. Low ${ }^{1 \dagger}$, S. C. Wang ${ }^{2}$ \\ and C. Larson ${ }^{3}$
}

In part 1 of this review, emerging practice to realise nanostructured metallic coatings by electrodeposition, anodising and electrophoresis has been considered. Conventional, aqueous electrolytes may be utilised in some cases if workpiece preparation and process conditions are well controlled. Such coatings can provide wear and corrosion resistance or a catalytic or high active area compared to more conventional coatings. An overview of the principles involved in deploying electrochemical techniques to produce nanostructured surfaces and factors influencing developments in this rapidly emerging field were considered. The strategies, which can be adopted to electrodeposit nanostructured metallic coatings, include grain refinement, application of a pulsed current, inclusion of nanoparticles into the coating and the use of nanoporous templates. In part 2, examples of nanostructured coatings and their properties are illustrated with research findings from the authors' laboratory and the literature. Nanostructured metallic coatings include nanocrystalline, functionally graded, nanocomposite and recently introduced hierarchical structures. The potential uses for these coatings in engineering industries (including tribology and energy conversion) are summarised. Finally, future developments necessary to realise and deploy the coatings in increasingly demanding environments are considered.

Keywords: Batteries, Electrodes, Electroplating, Electrophoresis, Energy conversion, Fuel cells, Nanoparticle, Nanotube, Tribology

\section{Examples of nanostructured surfaces}

Part 1 of this review ${ }^{1}$ considered the electrochemical processes, i.e. electrodeposition, anodising and electrophoresis, and the principles controlling their deployment, which can be used to create nanostructured surfaces. The first part of the review also lists and defines symbols used in equations and formulae. In Part 2, the authors examine the surfaces themselves, their properties and the applications increasingly opening up for them.

\footnotetext{
† Present address: WMG Centre, School of Engineering, University of Warwick, Coventry, CV4 7AL, UK

${ }^{1}$ Electrochemical Engineering Laboratory, University of Southampton, Highfield, Southampton, SO17 1BJ, UK

${ }^{2}$ National Centre for Advanced Tribology at Southampton and Materials Engineering Research Group, University of Southampton, Highfield, Southampton, SO17 1BJ, UK

${ }^{3}$ Glencree, 6 Claxton Rise, Long Clawson, Leics, LE14 4PH, UK

*Corresponding author, email electro@chemeng.fsnet.co.uk
}

\section{Nanocrystalline coatings}

Many design factors must be considered for electroplating good-quality multifunctional nanocrystalline coatings for tribological and other applications. Electroplating process-structure-property relationships are critically important in realising multifunctional coatings, e.g. those which combine controlled electrical conductivity with increased flexibility, such as Ni-graphite $^{2}$ or combat wear and corrosion while simultaneously lowering friction, including $\mathrm{Ni}-\mathrm{SiC}^{3}$ The nucleation and growth of nanocrystalline deposits can be tuned by controlling process parameters, such as electrolyte composition, $\mathrm{pH}$, temperature, current density, and current waveform, duration, etc; all these parameters can manipulate the grain size, phase structure and surface roughness, which in turn can design a coating to have multifunctional tribological properties, e.g. wear resistance, corrosion resistance and friction control.

For coatings to be effective in tribological applications, stringent criteria can include good adhesion, high mechanical hardness and toughness, high thermal 
and chemical stability, uniform and adequate thickness, smooth surface finish and low friction. The coatings must usually exhibit a dense morphology (i.e. no porosity with an open columnar grain boundary) and a strong cohesive bonding among grains. Coatings with porous columnar structure tend to wear quickly; poor cohesion between grains tends to result in fracturedominated sliding wear.

Coatings that are nanocrystalline and have high fracture toughness can often resist crack initiation along a sliding contact surface since the grains are extremely small and the morphology is often not necessarily anisotropic or columnar. Highly anisotropic and columnar structure can often result in a structurally weak coating and thus be susceptible to deformation or fracture. Nanosized grains with a large-grain boundary network can provide a condition for resisting crack initiation, e.g. if a crack initiates within a grain, the strong and thin grain boundaries may deflect and branch-out, leading to reduction of stress concentration area and arresting further crack growth.

\section{Functionally graded coatings}

The properties of multilayered or graded coatings can be tuned by varying the properties of individual layers that makeup the bulk coating. Typically, the hardness may be influenced by the levels of internal stress within these coatings. A high level of internal stress may be beneficial to the hardness of a coating but it can also be detrimental to the fatigue and wear resistance of coatings.

Figure $1 a$ suggests that the top layer provides a tribological function (e.g. wear and friction), intermediate layers provide transitional function (via changing the composition and structure properties of coatings) while the bottom layer provides an adhesion function for coating-substrate. A gradient $\mathrm{Ni}-\mathrm{P}$ alloy was

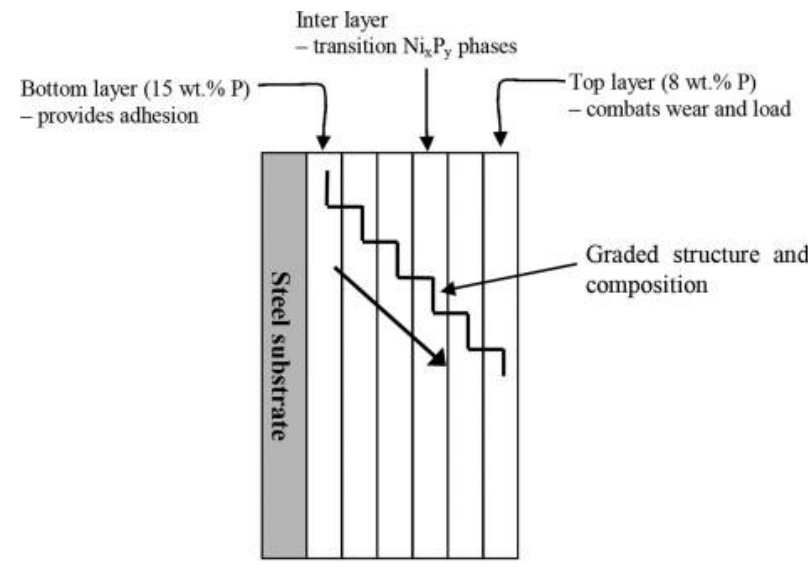

(a)

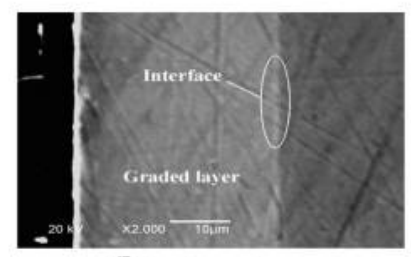

(b) $\overline{10} \mathrm{~m}$

1 Graded Ni-P coatings, showing $a$ the concept and $b$ an SEM cross-sectional image electroplated on steel substrates, with a graded change of phosphorus content in the direction of coating thickness. This coating was prepared from an electrolyte containing $240 \mathrm{~g} \mathrm{dm}^{-3}$ nickel sulphate, $30 \mathrm{~g} \mathrm{dm}^{-3}$ nickel chloride, $30 \mathrm{~g} \mathrm{dm}^{-3}$ boric acid, $20 \mathrm{~g} \mathrm{dm}^{-3}$ hypophosphorous acid, bath was kept at $70^{\circ} \mathrm{C}$ and a $\mathrm{pH}$ of 1.5 . $^{4,5}$ Six graded layers were electroplated by gradually changing the current density from 5 to $30 \mathrm{~A} \mathrm{dm}^{-2}$. Figure $1 b$ shows the scanning electron microscope (SEM) cross-sectional image for this coating. Results showed that the wear resistance of a graded Ni-P alloys coating was about twice as good as an ungraded coating, e.g. wear loss of $4 \times 10^{-5} \mathrm{~mm}^{3} \mathrm{~N}^{-1} \mathrm{~m}^{-1}$ for graded $\mathrm{Ni}-\mathrm{P}$ and $8 \times 10^{-5} \mathrm{~mm}^{3} \mathrm{~N}^{-1} \mathrm{~m}^{-1}$ for monolayer Ni-P $(8 \mathrm{wt}-\% \mathrm{P})$. Graded Ni-P deposits exhibited better wear resistance and lower friction coefficient than that of hard $\mathrm{Cr}$ deposits up to $600^{\circ} \mathrm{C}$. The formation and propagation of through thickness cracks within heat-treated $\mathrm{Ni}-\mathrm{P}$ deposits were effectively inhibited due to the introduction of a gradient composition.

In addition to electroplating multilayered metals and alloys, the multilayers can also contain nanosized particles. For example, single and mixed particles (1-4 $\mu \mathrm{m} \mathrm{Al}$ conductive particles and $60-80 \mathrm{~nm} \alpha-\mathrm{Al}_{2} \mathrm{O}_{3}$ non-conductive nanoparticles) in a nickel deposit were produced by varying the current density and concentration of particles in the bath. ${ }^{6}$ Each layer can provide a specific function, e.g. $\mathrm{Ni}$ for coating adhesion to substrate, Ni-15\% vol. $\mathrm{Al}_{2} \mathrm{O}_{3}$ as a transition layer and $\mathrm{Ni}-30 \%$ vol. $\mathrm{Al}_{2} \mathrm{O}_{3}$ for enhanced hardness. ${ }^{6}$

Another example is graded $\mathrm{SiC}$ particles in an $\mathrm{Ni}-\mathrm{Co}$ alloys coating. An increase in the applied current density from 2 to $15 \mathrm{~mA} \mathrm{~cm}^{-2}$ led to several effects including (a) an increase in the weight per cent of SiC particles in the coating, (b) an increase in the composition of cobalt in the Ni-Co alloys and (c) a decrease in the grain size of coating. Based on these results obtained for uniform electrodeposits, multifunctional, graded $\mathrm{Ni}-\mathrm{Co} / \mathrm{SiC}$ coatings were electrodeposited by incremental increase in the current density from 2 to $15 \mathrm{~mA} \mathrm{~cm}^{-2}$. ${ }^{7}$ Graded $\mathrm{SiC}$ layers in a $\mathrm{Ni}-\mathrm{Co}$ alloy coating showed superior mechanical properties and better wear resistance than the non-graded coating. ${ }^{7}$ For example, a bonding toughness peel test showed that the gradient coating had a very high bonding value, $c a .1 \mathrm{~kJ} \mathrm{~m}^{-2}$ compared to the non-graded one at $0.4 \mathrm{~kJ} \mathrm{~m}^{-2}$. The grain size near the interface in the graded coating was carefully matched to that of the substrate. The hardness of the graded coating increased gradually from $325 \mathrm{HV}$ (near its interface with the substrate) to $575 \mathrm{HV}$ (near the top surface of the coating), due to simultaneous effects from the increase in the amount of $\mathrm{SiC}$ particles in coating and the decrease in grain size of the coating. ${ }^{7}$ Additionally, the sliding distance for graded coating remained constant for over $200 \mathrm{~m}$ compared to a non-graded coating where the friction coefficient increased from a $50 \mathrm{~m}$ sliding distance.

\section{Nanocomposite coatings}

Nanocomposite coatings have the potential to offer multifunctional properties, since they can draw on properties found in the coating and the particles employed. It is possible to design coatings that can form self-replenishing, or self-lubricating tribofilms on their sliding surfaces; these are often called adaptive (or responsive) coatings. A multifunctional nanocomposite 
coating may adapt and follow the changing tribological environmental. For example, one component may provide corrosion resistance while a second component may provide wear resistance; or one component is active and provides both corrosion and wear resistance at room temperature, while a second component may become more active and provide corrosion and wear resistance at high temperatures.

Electroplating of nanoparticles into coatings is a popular method to extend the versatility of coatings and to confer them with multifunctional properties. For example, Fig. 2 shows transmission electron microscope (TEM) images of the cross-section of an electrodeposited nickel coating containing nanotubular titanium oxide particles. Nanotubular titanates are clearly embedded into the nickel coating with a reasonably uniform dispersion. ${ }^{8}$ Compared with a nickel coating containing irregularly shaped nanosized titanium dioxide particles, this composite coating has demonstrated several functionalities including (a) $>20 \%$ reduction in surface friction against steel, (b) $>28 \%$ enhancement in wear resistance in a three-body water-based abrasive wear test (steel counter body and $5 \mu \mathrm{m} \mathrm{SiC} \mathrm{particles),} \mathrm{(c)}$ $>100 \%$ improvement in coating hardness and $(\mathrm{d})>25 \%$ improvement in elastic modulus. It is postulated that the nanotubes in the nickel coating agglomerated to form a cross-linked and mesh-like matrix, which led to an enhancement in the dispersion-strengthening mechanism against external load force. The tribological properties of such coatings were effectively improved compared with a nickel coating reinforced with irregularly shaped titanium dioxide particles.

Composite coatings may be engineered to incorporate the properties of coating and lubricants, in such a way that they become compatible with, or complementary to, one another's performance and characteristics. If the phases are selected strategically, they can achieve self-lubricating capacity and provide low-friction and low-wear coefficients over a broad range of test conditions, temperatures, and environments. For example, in composite coatings, while one phase provides extreme resistance to wear and deformation, a second or third phase may preferentially react with the additives in oils to provide high lubricity and protection against wear. In such coating architectures, the properties of phases are strategically selected, so that they may become lubricious through tribological-chemical interactions with the chemical species in operating environments, thus enabling tools to operate even in the absence of additional liquid or solid state lubricants.
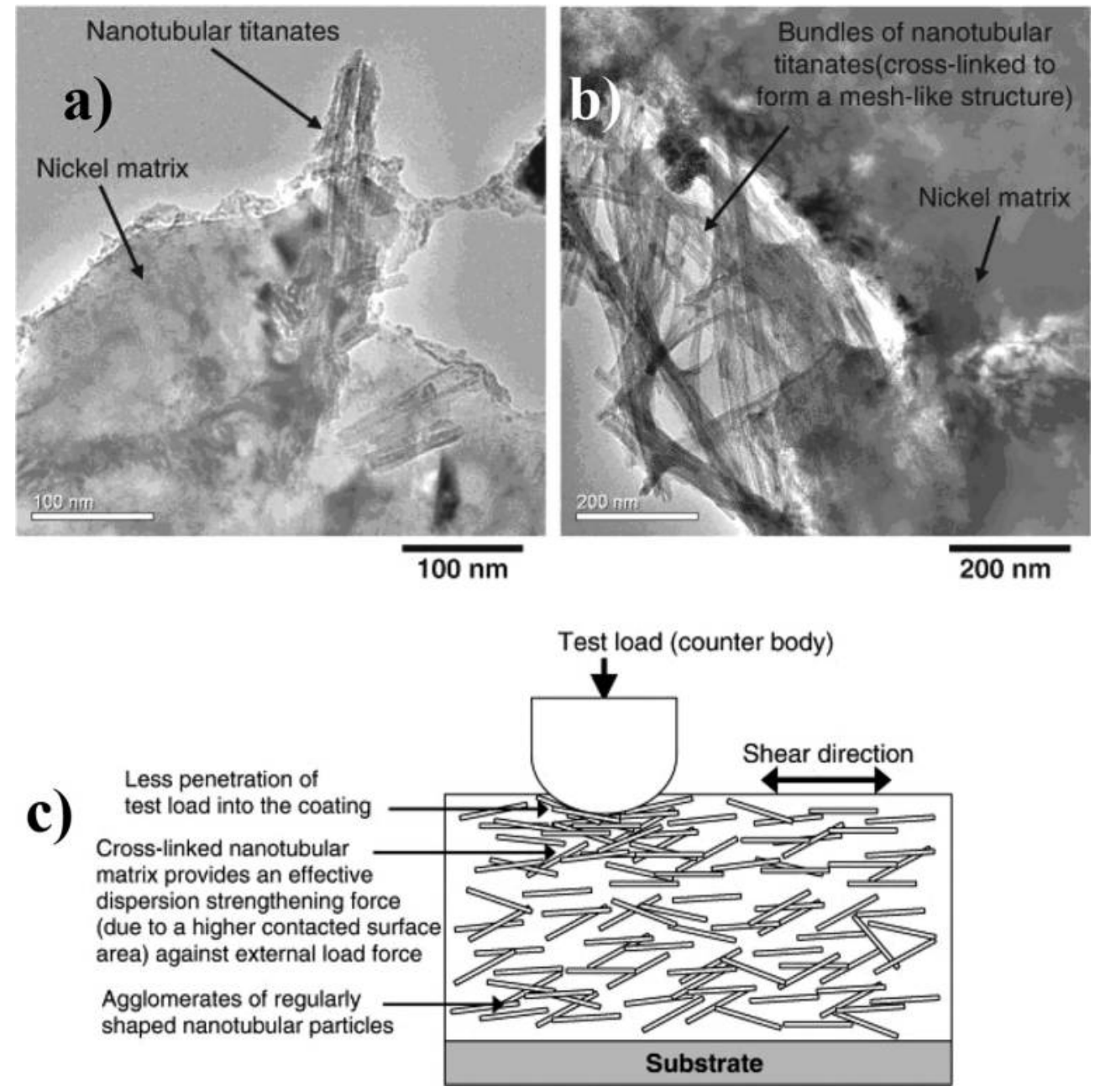

2 The cross-section of an electrodeposited nickel coating containing nanotubular titanium oxide (protonated titanate) particles (after Low et $a .^{8}$ ). a TEM image of the coating, showing titanate nanotubes within the nickel matrix and $b$ TEM image of the coating, showing bundles of titanate nanotubes cross-linked to form a mesh-like structure and $c$ sketch indicating strengthening and support mechanisms within the coating 
These coatings are highly desirable for many engineering applications but not easily electroplated. A simple concept for self-lubricating composite coating was realised by electroplating of metal with oil-containing microcapsules, ${ }^{9-12}$ as in Fig. 3. ${ }^{9}$ The copper-microcapsule composite coating was electroplated from an acid sulphate bath consisting of $200 \mathrm{~g} \mathrm{dm}^{-3}$ copper sulphate, $60 \mathrm{~g} \mathrm{dm}^{-3}$ sulphuric acid, $60 \mathrm{mg} \mathrm{dm}^{-3}$ hydrochloric acid and 20 vol.- $\%$ microcapsule emulsion. The hydrophobic capsules are $2-20 \mu \mathrm{m}$ in size. The liquid core material was organic siloxane, while the shell material was methyl cellulose. A current density of $3 \mathrm{~A} \mathrm{dm}^{-2}$ was used to plate the coating onto steel for $1 \mathrm{~h}$ at room temperature. Electrochemical analysis showed that the corrosion current through the copper-microcapsule coating was lowered to $1.5 \mu \mathrm{A} \mathrm{cm} \mathrm{cm}^{-2}$ compared to a plain copper coating at $60 \mu \mathrm{A} \mathrm{cm} \mathrm{cm}^{-2}$. Ageing trials showed that the microcapsules slowly released their oil contents to form a protective film on the coating surface.

\section{Hierarchical coatings}

Our fundamental understanding of nanostructured coatings improves alongside techniques for achieving such surfaces, and this section considers an example of a more complex nanostructure having distinct phases in its structure, which are arranged in a hierarchical fashion. The authors' Laboratory has recently demonstrated the possibility of achieving a 'nanotube within a nanotube' film on a metal surface, both nanotubular components having an electrochemical step in their formation. A titanium foil substrate has first been anodised to produce a nanotubular array. A hydrothermally synthesised protonated titanate nanotube has then been inserted into the tubes of this array by electrophoresis. ${ }^{13}$ Fig. $4 a$ shows the principles involved while Fig. $4 b$ shows SEM images of the resultant nanostructure. This opens up the possibility of inserting active materials, such as drugs, corrosion inhibitors or solid state lubricants into

a)

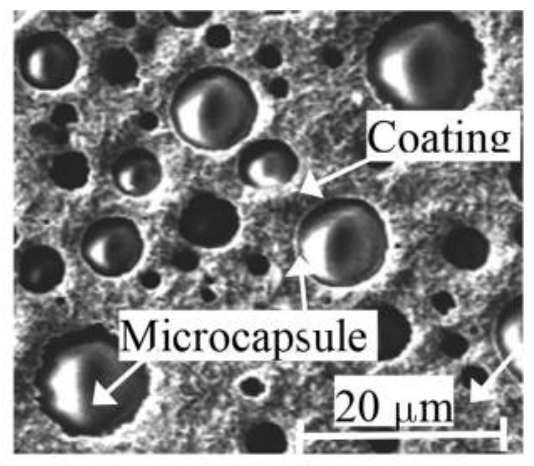

b)

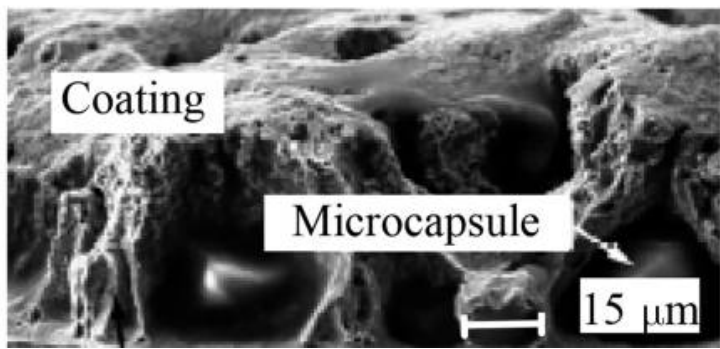

3 SEM images of electroplated copper containing liquid siloxane microcapsules (after Li et al. ${ }^{9}$ ). a View of the surface and $b$ cross-sectional view the inner tubes and arranging the outer tube structure to facilitate controlled release with time or in response to service conditions.

Examples of composites containing several nanosized components, at least one being achieved by electrodeposition or electrophoretic deposition, include Ni-polypyrrole-nanotubular titanates for corrosion resistance $^{8}$ and polyaniline incorporated in anodised nanotubes for improved corrosion protection. ${ }^{14}$

Enhancement of nanostructured surfaces can also be achieved by applying an overcoat. For example, Southampton University researchers have sputtered gold on $\mathrm{TiO}_{2}$ nanotube arrays previously formed by anodising titanium foil ${ }^{15}$ (Fig. 5). The resultant electrode structures have provided a robust and electrocatalytic surface for reduction of peroxide ${ }^{16}$ and oxidation of borohydride ions. ${ }^{17}$ in the direct borohydride fuel cell.

Taiwanese researchers have recently reported ${ }^{19}$ a hierarchical 3-D graphene sheet-carbon nanotube (GN-CNT) structure with good wetting properties, high porosity and large surface area, which could be homogeneously deposited with active amorphous manganese oxide $\left(\alpha-\mathrm{MnO}_{\mathrm{x}}\right)$ by potentiodynamic deposition. A twostep approach was used to fabricate the 3-D $\alpha-\mathrm{MnO}_{\mathrm{x}} /$ GNCNT composite with hierarchical porosity. In the first step, 1-D carbon nanotubes (CNTs) were inserted into the layers of chemically functionalised GN to construct a mesoporous GSeCNT structure via a simple solutionassembly process. In the second step, $\alpha-\mathrm{MnO}_{\mathrm{x}}$ was grown as flowery nanostructures with slender petals $(\mathrm{ca}$. 5-8 nm long) along the framework of a porous GNCNT matrix via potentiodynamic deposition. The flowery $\alpha-\mathrm{MnO}_{\mathrm{x}}$ nanostructure consisted of ultra-slender petals ( $\mathrm{ca}$. 5$8 \mathrm{~nm}$ ) on the framework of hierarchically porous GNCNT matrix. The use of $\alpha-\mathrm{MnO}_{\mathrm{x}}$ on the 3-D GNCNT material produces a specific capacitance of $\mathrm{MnO}_{\mathrm{x}}$ of $1200 \mathrm{~F} \mathrm{~g}^{-1}$, which is much higher than that of a pure $\alpha-\mathrm{MnO}_{\mathrm{x}}$ electrode. The specific energy and specific power of $\alpha-\mathrm{MnO}_{\mathrm{x}} / \mathrm{GNCNT}$ were $46.2 \mathrm{~W} \mathrm{~h} \mathrm{~kg}^{-1}$ and $33.2 \mathrm{~kW} \mathrm{~kg}^{-1}$, respectively.

Diverse hierarchical $\mathrm{ZnO}$ nanostructures, including porous nanoflakes, nanosheets and nanopillar arrays have been fabricated directly from poly-hydroxyethyl methacrylate hydrogel-coated electrodes. ${ }^{20}$ Hybrid $\mathrm{ZnO}$ hydrogel composite films could be formed at a low zinc concentration in the bath in a short electrodeposition time. At zinc concentrations above $0.01 \mathrm{~mol} \mathrm{dm}^{-3}$, a pure $\mathrm{ZnO}$ layer could be formed whereas a dual-layer structure consisting of a $\mathrm{ZnO} /$ polymer was obtained at lower zinc levels. SEM observations and XPS depth profiling were used to study $\mathrm{ZnO}$ nanostructure formation during the early stages of electrodeposition, and the authors proposed a growth mechanism to explain the formation of $\mathrm{ZnO} /$ hydrogel hybrid hierarchical nanostructures. The current-voltage characteristics of the $\mathrm{ZnO}$-hydrogel composite films under dark and ultraviolet (UV) illumination suggest potential applications in UV photodetection.

\section{Summary and developments}

\section{Summary}

Electroplating, anodising and electrophoresis are simple and versatile wet-processing methods to fabricate multifunctional nanostructured metallic coatings including 


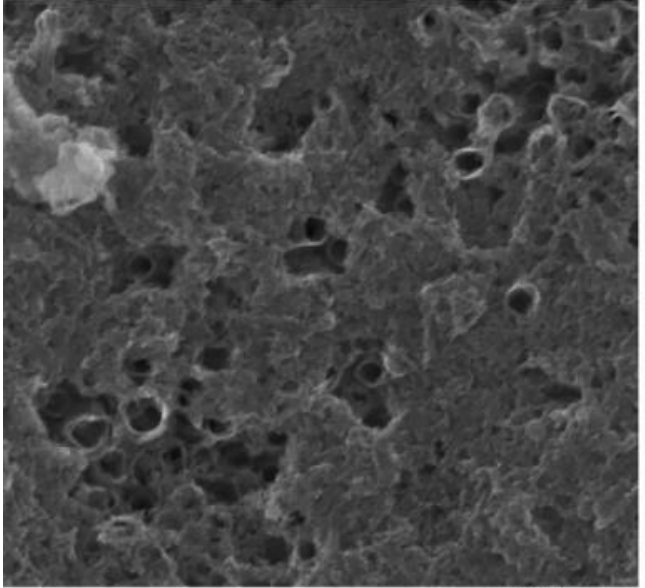

a)

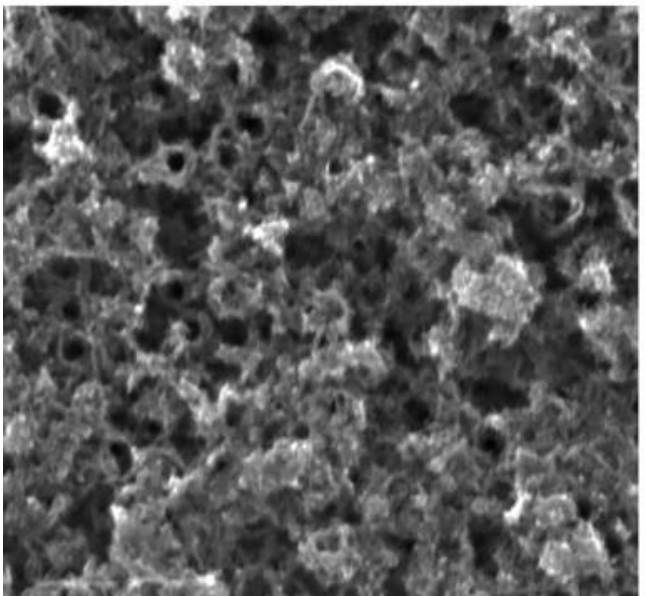

c)

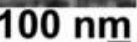

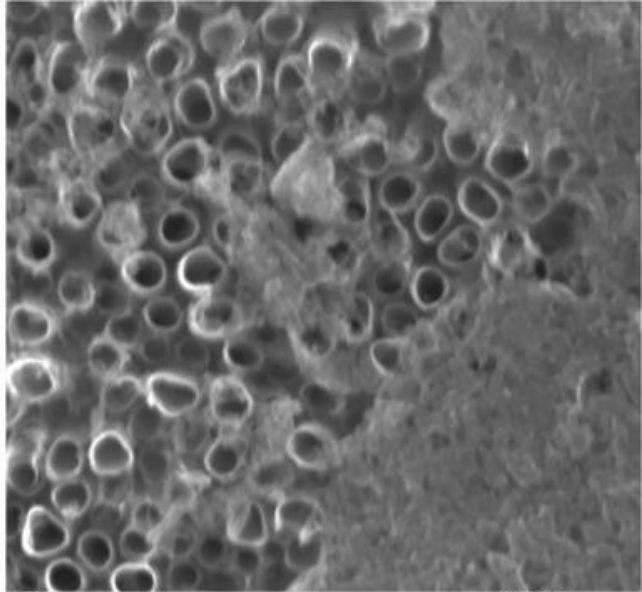

b)

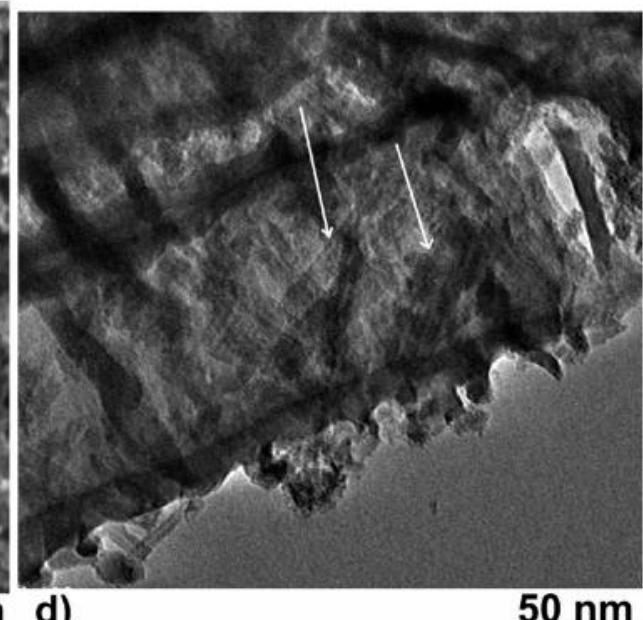

d)

$50 \underline{\mathrm{nm}}$

e)

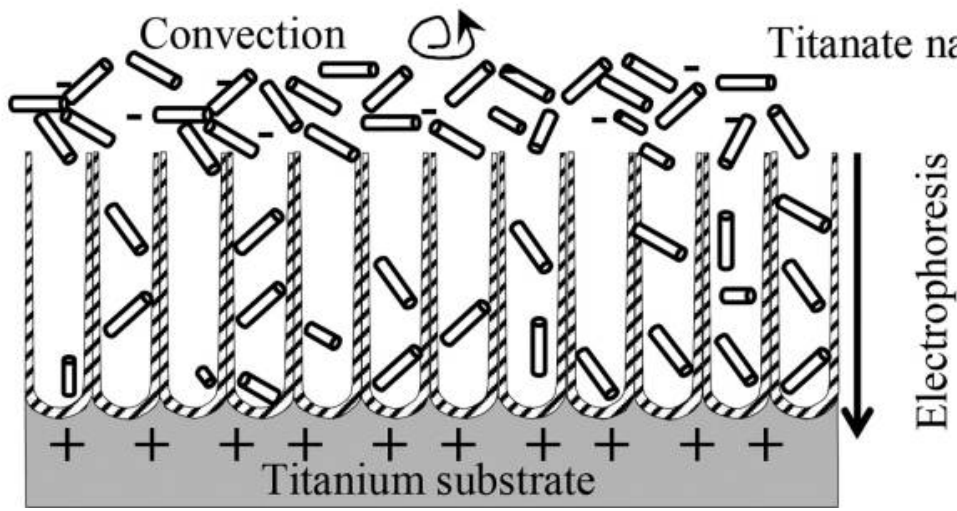

4 A hierarchical nanostructured coating demonstrating a 'nanotube-in-nanotube' strategy (after Bavykin, Passoni and Walsh ${ }^{13}$ ). a-c SEM images of protonated titanate nanotubes electrophoretically deposited on the surface of a $\mathrm{TiO}_{2}$ nanotube array in ethanol suspension at controlled stirring rates of $a 0 \mathrm{rpm}, b 50 \mathrm{rpm}, c 400 \mathrm{rpm}, d$ TEM image showing the crosssection of large $\mathrm{TiO}_{2}$ NT with incorporated TiNT (shown with arrows) obtained at $400 \mathrm{rpm}$. $e$ the electrophoretic deposition of protonated titanate (diameter $20 \mathrm{~nm}$, length $50 \mathrm{~nm}$ ) into the $150 \mathrm{~nm}$ diameter, $>1 \mu \mathrm{m}$ long pores of an anodic $\mathrm{TiO}_{2}$ nanotube array on a titanium foil substrate in the presence of strong electrolyte agitation using a magnetic stirrer

nanocrystalline, functionally graded and nanocomposite types. These nanostructures can be realised by methods, such as grain refinement, pulsed current, inclusion of nanoparticles into a coating and the use of hard or soft nanoporous templates. These approaches employ non-pressurised system and not excessively high temperatures to electroplate coatings. The coatings can provide several functional properties; thus are very attractive to combat tribological environments that require coatings, which have better durability and high performance, while being able to self-adapt to the increasingly harsh and rapidly changing condition of future tribological environments. Nanostructured metallic coatings that can perform under a wide range of 


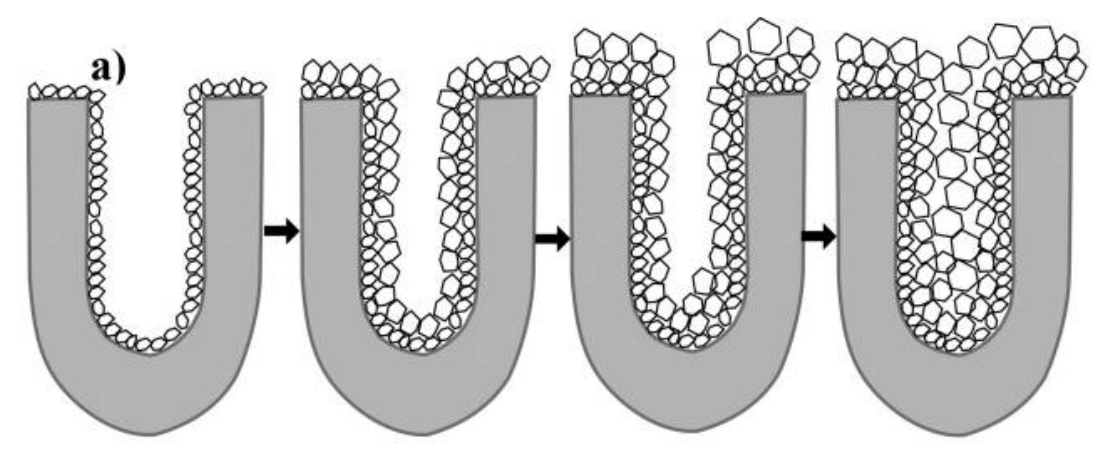

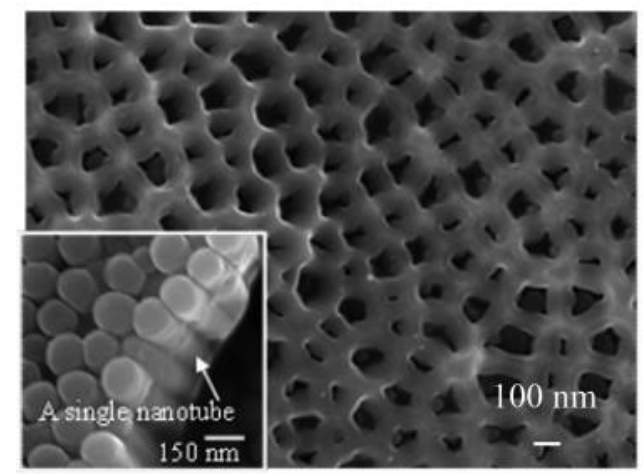

b) 'as-formed' $\mathrm{TiO}_{2}$ nanotubular array

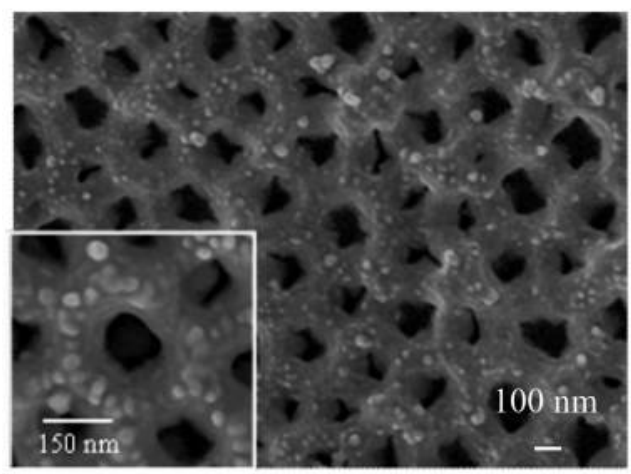

c) 10 minutes Au deposition

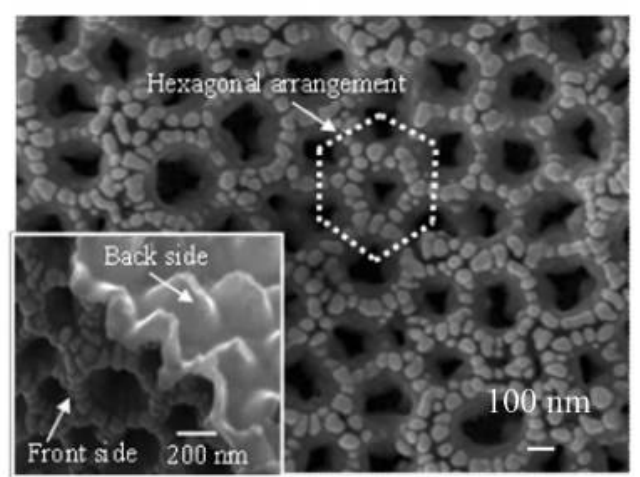

d) 20 minutes Au deposition

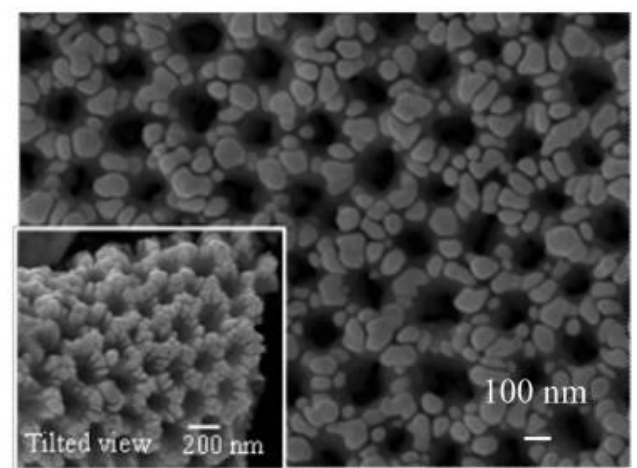

e) 30 minutes Au deposition

5 An example of a nanotubular array demonstrating a 'nano-on-nano' overcoating approach deploying sputtering of gold nanonodules to enhance the surface of an anodised $\mathrm{TiO}_{2}$ nanotube array on a titanium foil substrate (after Low et al. ${ }^{15,17}$ ). a A schematic showing gold nodule development around the titanium dioxide nanopores with time and SEM images of the coating at various gold deposition times (and loadings): $b-e$ SEM images with higher magnification inserts showing: $b$ as-formed $\mathrm{TiO}_{2}$ nanotubular array (and coating mass density) after $0 \mathrm{~min}, c 10 \mathrm{~min}\left(69 \mu \mathrm{g} \mathrm{cm}^{-2}\right), d 20 \mathrm{~min}\left(164 \mu \mathrm{g} \mathrm{cm}^{-2}\right)$ and $e 30 \mathrm{~min}\left(179 \mu \mathrm{g} \mathrm{cm}^{-2}\right)$

environmental conditions are increasingly sought to meet current demands and future projections.

\section{Emerging and future developments}

The rapid progress made in the realisation of nanostructures by surface finishing techniques raises several possibilities for future developments. In the case of codeposited inclusions, for example, liquid inside the capsules could be tailored to a variety of functional purposes. For example, capsules could be filled with (a) mineral oils for making surfaces, in ball bearings, which self-lubricate or (b) coloured liquids, fluorescent liquids or scented oils to realise metal parts that change colour or release an odour when they are damaged. Several different types of capsules could be incorporated inside a metal layer to display multi-functional properties. Coloured or scented particles in the top coating layer might signal wear or damage, while oil particles or chemically reactive particles in the deeper coating layer might effect self-repair of the coating/substrate or prevent further damage onto the substrate. Such architectures could sense the extent of wear, and could be designed to provide a warning before coating failure. For example, fluorescent particles can be placed in a particular area and known depth. If the coating is breached, illumination of this area could provide distinctive optical spectra, allowing an in situ detection of the state of wear. The increasing availability of advanced printing techniques, including 3 -D ones, might create the possibility of depositing profiled, multilayer deposits of metals, polymers and ceramics as well as a wide range of composites under computer control. The availability of digital signals from such coatings might provide an initial statement of their electrical (e.g. conductivity), physical (e.g. surface roughness) or electrochemical (e.g. corrosion resistance) 
characteristics. Such properties could be probed at intervals or monitored continuously, perhaps via a wireless link, to diagnose shelf- lifetime or highlight arduous in situ service conditions.

Among the many recent developments in nanostructured coatings via electrochemical techniques, a few final examples may be given to show emerging trends:

1. Direct deposition of a polymer film: anodic deposition of thick polypyrrole. ${ }^{20}$

2. Composites containing several nanosized components, at least one by electrodeposition or electrophoretic deposition, e.g. (a) polypyrrole-NT titanates for corrosion resistance, ${ }^{21}$ (b) titanate nanotubular composites and polyaniline incorporated in anodised nanotubes ${ }^{14}$ and (c) $\mathrm{MnO}_{2}$ 'nanoflorets' inserted into graphene nanosheets. ${ }^{18}$

3. Enhancement of nanostructured surfaces by use of a secondary coating, e.g. the sputtering of gold on $\mathrm{TiO}_{2}$ nanotube arrays previously formed by anodising titanium foil. ${ }^{15}$

4. Hierarchical, nanofeatures within nanostructures, e.g. the example of a nanotube-in-a nanotube. ${ }^{13}$

5. The realisation of biomaterial composite fibres containing nanomaterials by electrospinning of a chitosan/ titanate/ carbon nanotube dispersion. ${ }^{22}$

\section{Acknowledgement}

The authors are grateful to Professor Robert Wood, National Centre for Advanced Tribology at Southampton, for early discussions.

\section{References}

1. F. C. Walsh, C. Ponce de Leon, D. V. Bavykin, C. T. J. Low, S. Wang and C. Larson: Trans. IMF, 2015, 93, 209-224.
2. J. Lapinski, D. Pletcher and F. C. Walsh: Surf. Coat. Technol., 2011, 205, 5205

3. A. Sohrabi, A. Dolati, M. Ghorbani, A. Monfared and P. Stroeve: Mater. Chem. Phvs., 2010, 121, 497.

4. L. Wang, Y. Gao, Q. Xue, H. Liu and T. Xu: Surf. Coat. Technol., 2006, 200, 3719.

5. L. Wang, Y. Gao, T. Xu and Q. Xue: Appl. Surf. Sci., 2006, 252, 7361 .

6. L. Wang, J. Zhang, Y. Gao, Q. Xue, L. Hu and T. Xu: Scr. Mater., 2006, 55, 657.

7. S. M. Lari Baghal, M. H. Sohi and A. Amadeh: Surf. Coat. Technol., 2012, 206, 4032.

8. C. T. J. Low, J. O. Bello, J. A. Wharton, R. J. K. Wood, K. R. Stokes and F. C. Walsh: Surf. Coat. Technol., 2010, 205, 1856

9. Y. Li, H. Jiang, W. Huang and H. Tian: Appl. Surf. Sci., 2008, 254, 6865.

10. C. T. J. Low, R. G. A. Wills and F. C. Walsh: Surf. Coat. Technol., 2005, 201, 371

11. X. Xu, H. Liu, W. Li and L. Zhu: Mater. Lett., 2011, 65, 698.

12. X. Qing, Z. Qin and L. Ping: Trans. Nonferrous Met. Soc. China, 2011, 21, 2210.

13. D. V. Bavykin, L. Passoni and F. C. Walsh: Chem. Commun. (Camb.) , 2013, 49, 7007.

14. O. Zubillaga, F. J. Cano, I. Azkarate, G. Imbuluzqueta and M. Insaust: Trans. $I M F, 2009, \mathbf{8 7}, 315$

15. C. T. J. Low, M. de la Toba Corral and F. C. Walsh: Trans. IMF, 2011, 89, 44-48.

16. C. T. J. Low, C. Ponce de Leon and F. C. Walsh: J. Appl. Electrochem., 2014, 42, 169.

17. C. T. J. Low, C. Ponce de Leon and F. C. Walsh: Electrochem. Commun., 2012, 22, 166.

18. S. M. Li, Y. S. Wang, S. Y. Yang, C. H. Liu, K. H. Chang, H. W. Tien, N. T. Wen, C. C. M. Maa and C. C. Hu: J. Power Sources, 2013, 225, 347.

19. S. Dai, Y. Li, Z. Du and K. R. Carter: J. Electrochem. Soc., 2013, 160, D156-D162.

20. V. Caramia, C. T. J. Low, C. Ponce de Leon, F. C. Walsh and P. Herrasti: Trans. IMF, 2015, 93, 139-146.

21. P. Herrasti, A. N. Kulak, D. V. Bavykin, C. Ponce de Léon, J. Zekonyte and F. C. Walsh: Electrochim. Acta, 2011, 56, 1323-1328.

22. C. Dechakiatkrai, C. Lynam, K. J. Gilmore, J. Chen, S. Phanichphan, D. V. Bavykin, F. C. Walsh and G. G. Wallace: Adv. Eng. Mater, 2009, 11, B55. 